\title{
Anaplasmataceae closely related to Ehrlichia chaffeensis and Neorickettsia helminthoeca from birds in Central Europe, Hungary
}

\author{
Sándor Hornok (D) - Sándor A. Boldogh • Nóra Takács • Alexandra Juhász • \\ Jenő Kontschán • Dorottya Földi · Balázs Koleszár • Pál Morandini • \\ Miklós Gyuranecz • Sándor Szekeres
}

Received: 10 February 2020/Accepted: 7 April 2020/Published online: 21 April 2020

(C) The Author(s) 2020

\begin{abstract}
Increasing amount of data attest that (in the context of vector-borne infections) birds are not only important as hosts of blood-sucking arthropod vectors, but also as reservoirs of vector-borne pathogens. From 2015 to 2019 cadavers of 100 birds (from 45 species, nine orders) were collected in Hungary, and their organs were screened for DNA from a broad range of vector-borne bacteria with PCR and sequencing. Molecular analyses revealed the presence of Anaplasmataceae, and sequencing identified bacteria closely related to Neorickettsia helminthoeca and Ehrlichia chaffeensis in a Eurasian teal (Anas crecca)
\end{abstract}

Electronic supplementary material The online version of this article (https://doi.org/10.1007/s10482-020-01415-4) contains supplementary material, which is available to authorized users.

S. Hornok $(\bowtie) \cdot$ N. Takács · A. Juhász · B. Koleszár ·

S. Szekeres $(\bowtie)$

Department of Parasitology and Zoology, University of

Veterinary Medicine, Budapest 1078, Hungary

e-mail: Hornok.Sandor@univet.hu

S. Szekeres

e-mail: Sanyi.Szekeres@gmail.com

S. A. Boldogh

Department of Nature Conservation, Aggtelek National

Park Directorate, Jósvafő 3758, Hungary

J. Kontschán

Department of Zoology, Plant Protection Institute, Centre

for Agricultural Research, Budapest 1022, Hungary and a song thrush (Turdus philomelos), respectively. All samples were PCR negative for rickettsiae, borreliae, Francisella and Coxiella spp., as well as for piroplasms. To our knowledge, this is the first report of a Neorickettsia and an Ehrlichia sp., which belong to the phylogenetic groups of $N$. helminthoeca and E. chaffeensis, respectively, from Europe. The potential presence of these two vector-borne bacteria needs to be taken into account during future studies on the eco-epidemiology of Anaplasmataceae in Europe.

Keywords Vector-borne $\cdot$ Tick-borne $\cdot$ Rickettsia . Piroplasm · Borrelia $\cdot$ Francisella $\cdot$ Coxiella 


\section{Introduction}

Vector-borne microorganisms are those, which can be transmitted by blood-sucking arthropods or other invertebrate vectors between susceptible vertebrate hosts (Vaughan et al. 2012). In several regions of the globe even molecular "baseline data" are lacking on the occurrence of vector-borne pathogens in various vertebrate groups, therefore the emerging or receding character of these infections might be hard to assess. From an epidemiological point of view, birds are perhaps the most important to study in this context, because of their motility (migration habit) and frequent association with arthropod vectors, such as ticks (de la Fuente et al. 2015).

Birds are often reported as hosts of ticks and other blood-sucking arthropods, which may transmit vectorborne pathogens of veterinary-medical importance (de la Fuente et al. 2015; Farajollahi et al. 2011). However, compared to mammals, the reservoir role of birds appears to have deserved less attention from the point of view of vector-borne pathogens, as exemplified by the limited number of studies on borreliae (Ginsberg et al. 2005), rickettsiae (Hornok et al. 2014) and Anaplasmataceae (Keesing et al. 2012). Therefore, this study aimed at screening and identifying vector-borne bacteria and protozoa (rickettsiae, borreliae, Francisella and Coxiella spp., as well as piroplasms) in birds from Central Europe, Hungary. The results focus on Anaplasmataceae.

\section{Materials and methods}

One hundred bird cadavers (belonging to 45 species, nine orders: Supplementary file 1) were collected between January 2015 and January 2019, at three locations in north (Budapest, $\mathrm{n}=18$ ) and northeastern Hungary (Aggtelek National Park and its surroundings, $\mathrm{n}=40$; Eger, $\mathrm{n}=13$ ), as well as in western Hungary (Sopron, $n=7$ ) and other parts of the country (in total $\mathrm{n}=22$; in particular: Bugyi, $\mathrm{n}=1$; Dinnyés, $\mathrm{n}=1$; Gárdony, $\mathrm{n}=1$; Hajdúböszörmény, $\mathrm{n}=1$; Hajdúszoboszló, $\mathrm{n}=1$, Zánka, $\mathrm{n}=2$; not recorded, $n=15$ ). All birds were found dead due to natural causes or car hits, therefore no ethical permission was needed. Utilization of cadavers for scientific purposes was in accordance with the government decree 71/2015.[III.30.]. From the cadavers at least $200 \mu \mathrm{l}$ of EDTA-anticoagulated blood was collected, if possible. In addition, $100 \mathrm{mg}$ tissue samples were taken from the middle of organs which were in good condition (i.e. intact, not autolyzed), with sterile scalpel blade to exclude surface contamination. Tissues sampled for DNA extraction included the spleen, liver and heart muscle (Supplementary file 1), but other organs (lungs, kidneys, brain) were also preserved. All tissues were kept frozen at $-20{ }^{\circ} \mathrm{C}$ until processing. DNA was extracted with the QIAamp DNA Mini Kit (Qiagen, Hilden, Germany) following the manufacturer's instruction and including extraction control $(100 \mu \mathrm{l}$ phosphate-buffered saline processed together with the samples) in each set of samples to monitor cross contamination. All endo- or ectoparasites were collected and stored in 96\% ethanol.

In total, 273 DNA extracts and 12 extraction controls were screened for a broad range of vectorborne bacteria and piroplasms (Supplementary file 2). Investigations for the presence of Anaplasmataceae were performed in two steps (Table 1). The first step was a screening assay, which was followed by groupspecific PCRs, amplifying a short or long part of the 16S rRNA gene, respectively. This gene was chosen as the target of molecular-phylogenetic analyses, on account of its suitability for screening, as well as for genotyping Neorickettsia and Ehrlichia species (Vaughan et al. 2012; Rar and Golovljova 2011). All PCRs included appropriate positive and negative (nontemplate) controls. Positive controls for Anaplasmataceae were sequence-verified Anaplasma marginale from cattle blood; Ehrlichia sp. HG-T10 from tick and Neorickettsia sp. AVTI-128 from bird. For other vector-borne pathogens positive controls are listed in Supplementary file 2.

Purification and sequencing were performed at Biomi Ltd. (Gödöllö, Hungary). Sequences were aligned and compared to GenBank sequences by nucleotide BLASTn program (https://blast.ncbi.nlm. nih.gov). Phylogenetic analyses were performed with the Minimum Evolution method (Tamura Nei model) (Fig. 1), the unweighted pair group method with arithmetic mean (UPGMA) (Supplementary file 3) and Maximum Likelihood (ML) method (Jukes-Cantor model) (Supplementary file 4). All sequences retrieved from GenBank for phylogenetic analysis had 99-100\% coverage with ours. Phylogenetic analyses were done using MEGA 7.0 (Kumar et al. 2016). 


\section{Results}

All samples were PCR negative for rickettsiae, borreliae, Francisella and Coxiella spp., as well as for piroplasms. However, two samples were PCR positive for Anaplasmataceae, and were therefore analyzed further.

A new Neorickettsia genotype was detected in a Eurasian teal (Anas crecca: order Anseriformes). Neorickettsia DNA could be amplified from the blood sample, the kidneys, and the lungs. In this bird two fluke species were present: the blood fluke Bilharziella polonica (mounted on slide prior to knowing PCRpositivity of its host) and an Echinostoma sp. intestinal fluke (preserved in 96\% ethanol, processed for DNA extraction, and PCR negative for Anaplasmataceae). Molecular analysis of the new Neorickettsia genotype revealed the highest, 97.7-98.9\% (1224-1239/ $1253 \mathrm{bp}$ ) sequence identity with bacteria of the $N$. helminthoeca group reported from the USA (GenBank: U12457, KF661350 and KX462531). This was confirmed in the phylogenetic tree, because the new Neorickettsia genotype clustered together with $N$. helminthoeca-related isolates, and their separation from other neorickettsiae was strongly (100\%) supported (Fig. 1).

An Ehrlichia genotype was present in a song thrush (Turdus philomelos: order Passeriformes). Only the blood and spleen samples of this bird were PCR positive, but its liver, heart muscle, kidneys, lungs, and brain were PCR negative. Molecular analysis of this Ehrlichia genotype showed the highest, 99.1-99.5\% (1282-1287/1294 bp) sequence identity with Ehrlichia chaffeensis, reported from ruminants in China (KX505292) and Japan (AB454074) as well as humans in the USA (U60476). On the other hand, the Ehrlichia sp. from song thrush had lower, only 97.8-98.5\% (1266-1275/1294 bp) sequence identity with E. ruminantium (NR_074513), E. muris (AB013009), E. canis (EU439944) and 98\% (340/ $347 \mathrm{bp}$ ) identity with an Ehrlichia genotype recently reported from penguins (MK049840).

Phylogenetically, the avian Ehrlichia genotype reported here occupied a basal position to the group of American and/or Asian Ehrlichia chaffeensis isolates in the Minimum Evolution (Fig. 1), as well as in the UPGMA and ML trees (Supplementary files 3-4). Interestingly, this avian Ehrlichia genotype was $100 \%$ identical (690/690 bp) in its considerably 
Fig. 1 Minimum Evolution phylogenetic tree of Anaplasmataceae (with Rickettsia parkeri as outgroup) based on the $16 \mathrm{~S}$ rRNA gene. There were a total of 1227 positions in the final dataset. Genotypes from this study are highlighted with red color and bold accession numbers. For each item, the isolation source and country of origin are shown in parentheses between the species name and relevant GenBank accession number. The scale-bar indicates the number of substitutions per site

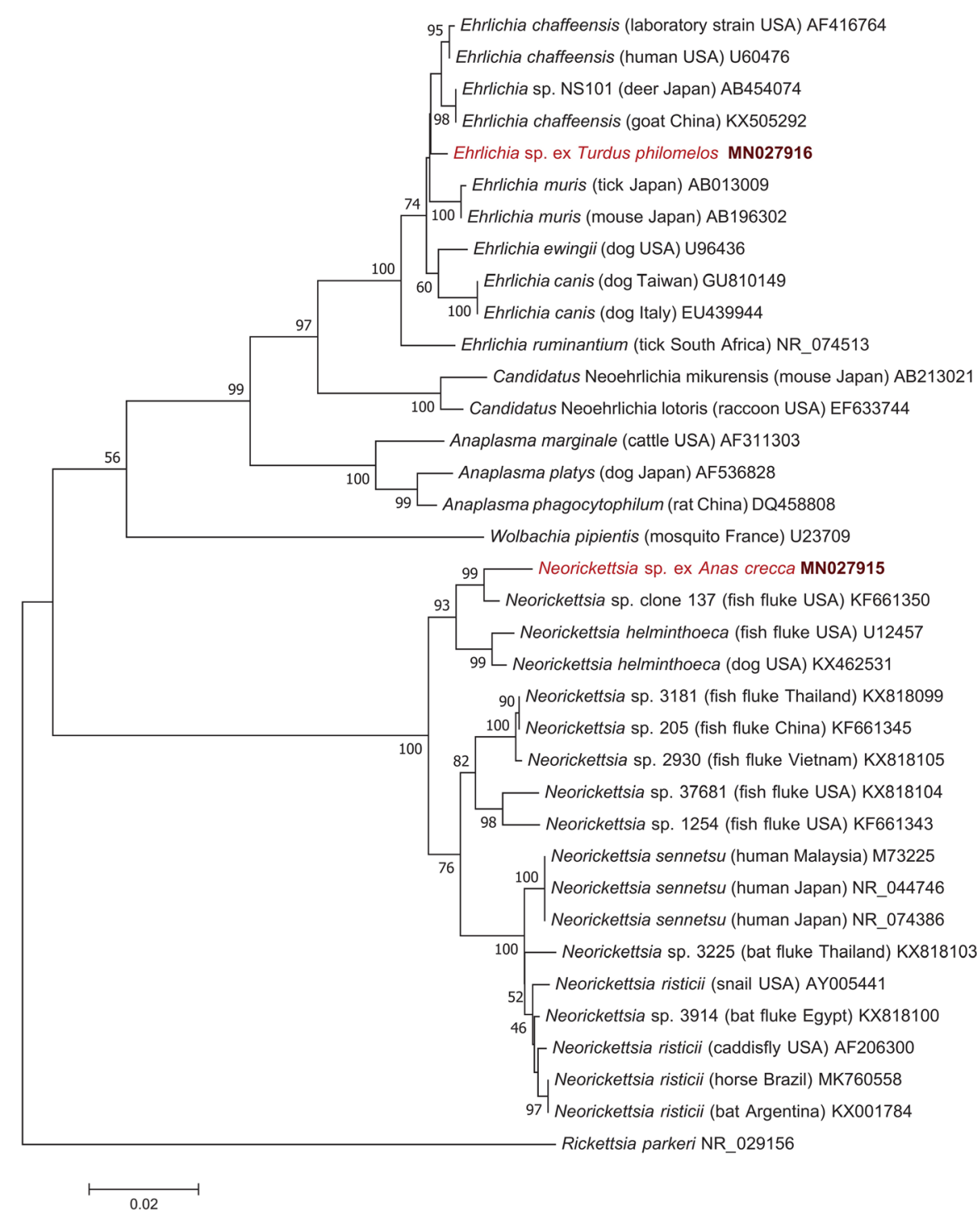

shorter 16S rRNA gene sequence with Ehrlichia sp. "It20" and "It40" reported from ticks (Ixodes turdus) in Japan (GenBank: LC386012 and LC386013).

New sequences were submitted to GenBank (accession numbers: MN027915 and MN027916 for the Neorickettsia and Ehrlichia sp., respectively).

\section{Discussion}

PCR-negativity of all analyzed specimens for rickettsiae, borreliae and piroplasms (for which birds are known to be susceptible: Hasle 2013) can be explained by either the lack of infection in examined birds, or very low levels of bacteraemia/parasitaemia not detectable by conventional PCRs used here. At the same time, even highly sensitive real-time PCRs were unable to show infection with $F$. tularensis and $C$. burnetii or closely related species in birds of this study, suggesting that the majority of analyzed bird species (e.g. songbirds: order Passeriformes, represented by 46 out of 100 individuals here) do not carry the causative agents of tularemia and Q-fever in relevant regions of Hungary. This is in line with literature data, because $F$. tularensis and $C$. burnetii often have the highest prevalence in diurnal birds of prey (Riemann et al. 1977; Padeshki et al. 2010), of 
which only 13 individuals (Supplementary file 1: order Accipitriformes) were included in the present study.

Bacteria transmitted to birds by arthropod $v s$ fluke vectors may have different host-associations. Trushes (family Turdidae) are frequently reported to have the highest rate of tick infestation among songbirds (order Passeriformes) (Klaus et al. 2016), and this tendency may explain why the single PCR positivity for a genotype closely related to tick-borne ehrlichiae was detected in a song thrush here. On the other hand, flukes can be most often found in waterfowl and aquatic birds (Coles 2007), as exemplified by order Anseriformes in the present study. This order includes the Eurasian teal, in which a genotype closely related to fluke-associated neorickettsiae was detected.

Bacteria of the genus Neorickettsia are obligate intracellular endosymbionts of digenean flukes (Platyhelminthes: Digenea), from which they can also pass into vertebrates, inducing severe disease. Among the latter, salmon poisoning disease (SPD) is caused by $N$. helminthoeca. This species affects canids following ingestion of fluke-infected salmonid fish, and is known to occur in the western Pacific coast of North America, and in South America (Vaughan et al. 2012). To our knowledge, this is the first report of a Neorickettsia sp., belonging to the phylogenetic group of $N$. helminthoeca, from Europe. Neorickettsiae have been reported from at least six families of flukes in North America and Asia, which include species associated with (piscivorous) birds as final hosts (e.g. Lecithodendriidae, Schistosomatidae and Echinostomatidae: Vaughan et al. 2012), and these families are represented by several species in Hungary (Edelényi 1974). Nevertheless, in the present case the single Echinostoma specimen from the neorickettsia-positive bird turned out to be PCR negative and blood flukes could not be analyzed molecularly, leaving the fluke vector of this new neorickettsia genotype open to future studies. To our knowledge, this is also the first molecular evidence for a Neorickettsia species (closely related to $N$. helminthoeca) in the blood of any bird species.

Regarding other Anaplasmataceae, while there are several studies which demonstrated the presence of Anaplasma phagocytophilum in birds, particularly thrushes (Passeriformes: Turdidae) both in North America (Daniels et al. 2002) and in Europe (de la Fuente et al. 2005), there appear to be only two previous reports on the occurrence of Ehrlichia spp. in birds (order Falconiformes: Machado et al. 2012; order Sphenisciformes: Muñoz-Leal et al. 2019), both from South America. Unfortunately, both studies were based on short (approximately $350 \mathrm{bp}$ long) $16 \mathrm{~S}$ rRNA gene sequences, having only $30 \%$ coverage with ours, which therefore could not be included in the present phylogenetic analyses.

Taken together, this is the first finding of Ehrlichiainfection in birds in Europe, and in any passeriform bird species in a worldwide context. Moreover, the new Ehrlichia genotype detected in a songbird here is most closely related to E. chaffeensis, the causative agent of human monocytic ehrlichiosis with the highest number of cases in North America. Although seropositivity to E. chaffeensis was also recorded outside this main range (i.e., in southern Europe, Middle East and southern Asia), DNA was not detected in any of these cases (Rar and Golovljova 2011). In its shorter fragment of the 16S rRNA gene, the bird-associated Ehrlichia genotype detected here was most closely related to an Ehrlichia genotype reported from ticks (Ixodes turdus) in Japan (Taira et al. 2019). Interestingly, this tick species is associated with birds, particularly from the order Passeriformes (several families, including Turdidae), but it is only known to occur in the eastern Palaearctic far from Europe (Yamaguti et al. 1971). It is therefore an unlikely vector in the present context.

The new Ehrlichia genotype shown here to be present in a song thrush (Turdus philomelos) confirmed the potential epidemiological significance of thrushes as reservoirs of Anaplasmataceae from at least two genera: Anaplasma (as already known) and Ehrlichia (as shown here).

Acknowledgements Open access funding was provided by the University of Veterinary Medicine (ÁTE). The authors thank the help by Dr. Gábor Majoros in identifying worm species. The authors are also grateful to Ms. Ciara Reynolds for English editing.

Author contributions SH conceived the study, designed primer, performed sequence analyses and GenBank submission, wrote the manuscript. $\mathrm{SAB}, \mathrm{AJ}, \mathrm{BK}, \mathrm{PM}$ provided several important samples for the study. NT and JK performed molecular and phylogenetic analyses, respectively. DF and MG performed Francisella, Coxiella screening. SS contributed to study design and manuscript writing, extracted DNA. All authors read and approved the final version of the manuscript. 
Funding This study was funded by OTKA 115854 (NKFIH 130216) and molecular analyses by the Aggtelek National Park Directorate.

Data availability The sequences obtained and/or analyzed during the current study are deposited in GenBank under accession numbers MN027915 and MN027916 for the Neorickettsia and Ehrlichia sp., respectively. All other relevant data are included in the manuscript and the references.

\section{Compliance with ethical standards}

Conflict of interest The authors declare that they have no conflict of interests.

Ethical approval All birds were found dead due to natural causes, therefore no ethical permission was needed. Utilization of cadavers for scientific purposes was in accordance with the law 71/2015.[III.30.].

Open Access This article is licensed under a Creative Commons Attribution 4.0 International License, which permits use, sharing, adaptation, distribution and reproduction in any medium or format, as long as you give appropriate credit to the original author(s) and the source, provide a link to the Creative Commons licence, and indicate if changes were made. The images or other third party material in this article are included in the article's Creative Commons licence, unless indicated otherwise in a credit line to the material. If material is not included in the article's Creative Commons licence and your intended use is not permitted by statutory regulation or exceeds the permitted use, you will need to obtain permission directly from the copyright holder. To view a copy of this licence, visit http://creativecommons.org/licenses/by/4.0/.

\section{References}

Brown GK, Martin AR, Roberts TK, Aitken RJ (2001) Detection of Ehrlichia platys in dogs in Australia. Aust Vet J 79:554-558

Coles BH (2007) Parasitic disease of birds. Essentials of avian medicine and surgery. Blackwell Publishing Ltd, Hoboken, pp 313-333

Daniels TJ, Battaly GR, Liveris D, Falco RC, Schwartz I (2002) Avian reservoirs of the agent of human granulocytic ehrlichiosis? Emerg Infect Dis 8:1524-1525

de La Fuente J, Naranjo V, Ruiz-Fons F, Höfle U, Fernández De Mera IG, Villanúa D, Almazán C, Torina A, Caracappa S, Kocan KM, Gortázar C (2005) Potential vertebrate reservoir hosts and invertebrate vectors of Anaplasma marginale and A. phagocytophilum in central Spain. Vector Borne Zoonotic Dis 5:390-401

de la Fuente J, Estrada-Peña A, Cabezas-Cruz A, Brey R (2015) Flying ticks: anciently evolved associations that constitute a risk of infectious disease spread. Parasit Vectors 8:538
Edelényi B (1974) Flukes II.-Trematodes II. Flukes with indirect development-Digenea. Fauna Hungariae 117:1-344 [in Hungarian]

Farajollahi A, Fonseca DM, Kramer LD, Marm Kilpatrick A (2011) "Bird biting" mosquitoes and human disease: a review of the role of Culex pipiens complex mosquitoes in epidemiology. Infect Genet Evol 11:1577-1585

Ginsberg HS, Buckley PA, Balmforth MG, Zhioua E, Mitra S, Buckley FG (2005) Reservoir competence of native North American birds for the lyme disease spirochete, Borrelia burgdorferi. J Med Entomol 42:445-449

Greiman SE, Tkach VV, Pulis E, Fayton TJ, Curran SS (2014) Large scale screening of digeneans for Neorickettsia endosymbionts using real-time PCR reveals new Neorickettsia genotypes, host associations and geographic records. PLoS ONE 9:e98453

Hasle G (2013) Transport of ixodid ticks and tick-borne pathogens by migratory birds. Front Cell Infect Microbiol $3: 48$

Hornok S, Kováts D, Csörgő T, Meli ML, Gönczi E, Hadnagy Z, Takács N, Farkas R, Hofmann-Lehmann R (2014) Birds as potential reservoirs of tick-borne pathogens: first evidence of bacteraemia with Rickettsia helvetica. Parasit Vectors 7:128

Keesing F, Hersh MH, Tibbetts M, McHenry DJ, Duerr S, Brunner J, Killilea M, LoGiudice K, Schmidt KA, Ostfeld RS (2012) Reservoir competence of vertebrate hosts for Anaplasma phagocytophilum. Emerg Infect Dis 18:2013-2016

Klaus C, Gethmann J, Hoffmann B, Ziegler U, Heller M, Beer M (2016) Tick infestation in birds and prevalence of pathogens in ticks collected from different places in Germany. Parasitol Res 115:2729-2740

Kumar S, Stecher G, Tamura K (2016) MEGA7: molecular evolutionary genetics analysis version 7.0 for bigger datasets. Mol Biol Evol 33:1870-1874

Machado RZ, André MR, Werther K, de Sousa E, Gavioli FA, Alves Junior JR (2012) Migratory and carnivorous birds in Brazil: reservoirs for Anaplasma and Ehrlichia species? Vector Borne Zoonotic Dis 12:705-708

Muñoz-Leal S, Clemes YS, Lopes MG, Acosta ICL, Serpa MCA, Mayorga LFSP, Gennari SM, González-Acuña D, Labruna MB (2019) Novel Ehrlichia sp. detected in Magellanic penguins (Sphenicus magellanicus) and in the seabird tick Ixodes uriae from Magdalena Island, southern Chile. Ticks Tick Borne Dis 10:101256

Padeshki PI, Ivanov IN, Popov B, Kantardjiev TV (2010) The role of birds in dissemination of Francisella tularensis: first direct molecular evidence for bird-to-human transmission. Epidemiol Infect 138:376-379

Pusterla N, Chae J-S, DeRock E, Madigan JE (2000) One-tube PCR for the detection of the Ehrlichia phagocytophila genogroup. Vet Rec 147:22-23

Rar V, Golovljova I (2011) Anaplasma, Ehrlichia, and "Candidatus Neoehrlichia" bacteria: pathogenicity, biodiversity, and molecular genetic characteristics, a review. Infect Genet Evol 11:1842-1861

Riemann H, Behymer D, Fowler M, Ley D, Schultz T (1977) Serological investigation of captive and free living raptors. Raptor Res 11:104-111 
Taira M, Ando S, Kawabata H, Fujita H, Kadosaka T, Sato H, Monma N, Ohashi N, Saijo M (2019) Isolation and molecular detection of Ehrlichia species from ticks in western, central, and eastern Japan. Ticks Tick Borne Dis 10:344-351

Vaughan JA, Tkach VV, Greiman SE (2012) Neorickettsial endosymbionts of the Digenea: diversity, transmission and distribution. Adv Parasitol 79:253-297
Yamaguti N, Tipton VJ, Keegan HL, Toshioka S (1971) Ticks in Japan, Korea and Ryukyu Islands. Brigham Young Univ Sci Bull Biol Ser 15:1-226

Publisher's Note Springer Nature remains neutral with regard to jurisdictional claims in published maps and institutional affiliations. 